\title{
Non-pharmacological Management of Muscular Pain Secondary to Cerebral Palsy
}

\author{
Krishna N Sharma ${ }^{1}$, Kuki Bordoloi ${ }^{2}$, Ankita Kashyap ${ }^{3}$, Mrityunjay Sharma ${ }^{4}$ and Jyoti Sharma ${ }^{5}$ \\ ${ }^{1}$ Victoria University, Uganda \\ ${ }^{2}$ Gauhati Medical College, India \\ ${ }^{3}$ Department of Medicine, Gajraraja Medical College, India \\ ${ }^{4}$ Department of Respiratory Medicine, Banaras Hindu University, India \\ ${ }^{5} \mathrm{MGH}$ MedicalCollege, India
}

Submission: February 19, 2018; Published: March 19, 2018

*Corresponding author: Krishna N Sharma, Victoria University, Victoria Towers, Plot 1-13, Jinja Road, Kampala, Uganda, Email: me@drkrishna.co.in

\begin{abstract}
Cerebral palsy is the most common cause of physical disability in childhood. Muscular pain is one of the commonest secondary problem for cerebral palsy patients. Since there are very less literature available on the muscular pain management secondary to cerebral palsy, this paper highlights relevant aspects of non-pharmacological pain management.
\end{abstract}

Keywords: Muscular pain; Cerebral palsy; Non-pharmacological management; Physiotherapy; Complementary and alternative medicine

\section{Introduction}

Cerebral Palsy (CP) is a group of disorders of the development of movement and posture, causing activity limitations that are attributed to non-progressive disturbances occurring in the developing fetal or infant brain [1]. It is the most common cause of physical disability in childhood which affects ranging from 1.5 to more than 4 per 1,000 live births [1-6]. Cerebral palsy patients suffer from several secondary conditions, including muscular pain [7].

\section{Muscular Pain}

Muscular pain becomes a serious secondary problem for cerebral palsy patients [8]. A survey carried out in Norway on 406 persons with Cerebral Palsy (mean age -34 years), nearly one-third of the adults complained of chronic musculoskeletal pain. Pain was associated with gender, chronic fatigue, low life satisfaction and deteriorating physical function [9]. The prevalence of pain increases with time [8-10]. Back, neck and lower extremities have been reported to be the most common pain in the cerebral palsy [9\&10]. Patients with multilevel surgery have also complained of myofascial pain syndrome [11\&12]. The muscular pain may be associated with spasticity, impairments, dysfunctions, limited mobility [8], positioning issues, stretching, and bracing [13].

\section{Assessment and Evaluation}

There are several tools that may be used to evaluate the intensity of muscular pain. Pain Assessment Instrument for Cerebral Palsy (PAICP) is designed specially for the cerebral palsy patients [14]. Since the muscular pain may be due to joint dysfunctions too, various tests may be used to assess the underlying cause. Even subtle joint dysfunctions can be diagnosed by several sensitive tests like modified prayer test [15].

\section{Non-pharmacological management}

Since its possible inception in 460 BC, Physiotherapy has been helping patients with Cerebral Palsy for long [16]. The first Cerebral Palsy Clinic in United States of America (USA) was held 70 years ago on the 25th August, 1947 [17] and the first high frequency low amplitude current apparatus specially for cerebral palsy children was patented in 1985 [18]. Since then, there has been much development in pain management. The commonly used interventions are hot packs, ice packs, exercises, massage, stretching proprioceptive training, proprioceptive neuromuscular facilitation, TENS, IFT [8,19-21].

Though there are not many studies on manual therapy for pain management in cerebral palsy, various techniques may be 
effective in principles, if it is due to joint dysfunction or nerve entrapment [22-30]. Complementary and Alternative Medicine like music therapy, acupressure and acupuncture are claimed to have relieving effect on pain [31-37].

\section{Conclusion}

Muscular pain, especially in neck, back and lower extremities is a serious secondary problem for cerebral palsy patients and its prevalence increases with time. Various physiotherapy as well as complementary and alternative non-pharmacological medical interventions including but not limited to hot packs, ice packs, exercises, massage, stretching proprioceptive training, proprioceptive neuromuscular facilitation, TENS, IFT, music therapy, acupressure and acupuncture can be helpful in pain management.

\section{References}

1. Bax M, Goldstein M, Rosenbaum P, Leviton A, Paneth N, et al. (2005) Proposed definition and classification of cerebral palsy. Dev Med Child Neurol 47(8): 571-576.

2. Arneson CL, Durkin MS, Benedict RE, Kirby RS, Yeargin-Allsopp M, et al. (2009) Prevalence of Cerebral Palsy: Autism and Developmental Disabilities Monitoring Network, Three Sites, United States, 2004. Disability and Health Journal 2(1): 45-48.

3. Bhasin TK, Brocksen S, Avchen RN, Van Naarden Braun K (2006) Prevalence of four developmental disabilities among children aged 8 years-Metropolitan Atlanta Developmental Disabilities Surveillance Program, 1996 and 2000. MMWR Surveillance Summaries 55(1): 1-9.

4. Paneth N, Hong T, Korzeniewski S (2006) The descriptive epidemiology of cerebral palsy. Clinics in Perinatology 33(2): 251-267.

5. Surveillance of Cerebral Palsy in Europe (2002) Prevalence and characteristics of children with cerebral palsy in Europe. Developmental Medicine and Child Neurology 44(9): 633-640.

6. Winter S, Autry A, Boyle C, Yeargin-Allsopp M (2002) Trends in the prevalence of cerebral palsy in a population-based study. Pediatrics 110(6): 1220-1225.

7. Gajdosik CG, Cicirello N (2001) Secondary Conditions of the Musculoskeletal System in Adolescents and Adults with Cerebral Palsy. Physical \& Occupational Therapy in Pediatrics 21(4): 49-68.

8. Schwartz L, Engle JM, Jensen MP (1999) Pain in persons with cerebral palsy. Arch Phys Med Rehab 80(10): 1243-1246.

9. Jahnsen R, Villien L, Aamodt G, Stanghelle JK, Holm I (2004) Musculoskeletal pain in adults with cerebral palsy compared with the general population. Med 36(2): 78-84.

10. Opheim A, Jahnsen R, Olsson E, Stanghelle JK (2009) Walking function, pain, and fatigue in adults with cerebral palsy: a 7-year follow-up study. Developmental Medicine \& Child Neurology 51(5): 381-388.

11. Upadhyay AK, Upadhyay GA, Sharma KN (2014) Incidence of Myofascial Pain Syndrome in Cerebral Palsy Patients Post Multilevel Surgery: A Retrospective Study. Scientific Research Journal of India 3(1): 9-14.

12. Upadhyay GA, Upadhyay AK, Sharma KN (2014) Documentation of Complications Following Multilevel Surgeries in Cerebral Palsy. Scientific Research Journal of India 3(1): 1-8.

13. Vogtle LK (2009) Pain in adults with cerebral palsy: impact and solutions. Dev Med Child Neurol 4: 113-21.

14. Boldingh EJ, Bruggen MAJ, Lankhorst GJ, Bouter LM (2004) Assessing Pain in Patients With Severe Cerebral Palsy: Development, Reliability, and Validity of a Pain Assessment Instrument for Cerebral Palsy. Arch Phys Med Rehabil 85: 758-766.

15. Sharma KN (2014) The "Modified Prayer Test": a new clinical test for the diagnosis of anterosuperior dysfunction of sternoclavicular joint. Scientific Research Journal of India 3(4): 1-4.

16. Sharma KN (2012) Exploration of the History of Physiotherapy Scientific Research Journal of India 1(1): 19-22.

17. Sharma KN, Bordoloi K, Kashyap A, Sharma M, Sharma J (2018) Historical Roots of Physical Therapy Equipment for Cerebral Palsy. Journal of Yoga and Physiotherapy 3(5):1-2.

18. Sharma KN (2014) Unheard Historical Physiotherapy Inventions. Create Space USA.

19. Bordoloi K, Sharma N (2012) Effectiveness of Proprioceptive Training over Strength Training in Improving the Balance of Cerebral Palsy Children with Impaired Balance. Scientific Research Journal of India 1(1): 23-36.

20. Sharma KN (2012) PNF Made Easy: An Illustrated Guide. Create Space USA.

21. Sharma KN (2012) Handbook of Proprioceptive Neuromuscular Facilitation: Basic Concepts and Techniques. Saarbrucken Germany.

22. Franklin CB, Thomas VA, Dongho GBD, Faustin AT, Sharma KN (2018) Conventional Physiotherapy And Additional Krishna's Kinetikinetic Manual Therapy (KKMT) For Knee Osteoarthritis Rehabilitation: A Comparative Study. International Journal of Advanced Research and Publications 2(1): 54-58.

23. Sharma KN, Kathuria CB (2017) Practical guide on Krishna's Kinetikinetic Manual Therapy- Peripheral Joint Mobilization. Mau: Academy of KKMT.

24. Lolita FA, Sharma KN (2017) Effectiveness of KKMT 3D Mobilization vs Mulligan Mobilization in Knee Pain. Create Space USA.

25. Ngwe DH, Sharma KN (2016) Effectiveness of Mulligan vs KKMT on Non-Specific Shoulder Pain. Create Space USA.

26. Sharma KN (2016) KKMT ${ }^{\circledR}$ Mobilization-The Upper Extremities. Mau: Academy of KKMT.

27. Sharma KN (2016) KKMT Mobilization Peripheral Joints. J Nov Physiother 6(5): 62.

28. Sharma KN (2015) 5 Minutes Joint Pain Management. Create Space USA.

29. Raissa BL, Sharma KN (2017) Evaluating the Effectiveness of Sciatic Nerve Mobilisation in Sciatica. Create Space USA.

30. Kathuria CB, Bordoloi K, Kashyap A, Sharma M, Sharma J (2018) KKMT Joint Mobilization: Scientific Reconciliation of the Principles and Techniques. Journal of Yoga and Physiotherapy 3(5): JYP.MS.ID.555622.

31. Sharma KN (2016) Practical Music Therapy. Create Space USA.

32. Sharma KN (2013) Atlas of Acupuncture Points. Create Space USA.

33. Sharma KN (2013) Neuro-Acupuncture Made Easy: An Illustrated Guide. Create Space USA.

34. Sharma KN (2013) Acupuncture for Cerebral Palsy Simplified: An Illustrated Guide. Create Space, USA.

35. Sharma KN (2013) Acupuncture in Neurological Conditions: An Illustrated Guide. Create Space USA.

36. Sharma KN (2013) Neuro-Acupressure Made Easy. Create Space, USA.

37. Sharma KN (2013) Acupressure for Cerebral Palsy Made Easy: An Illustrated Self Treatment Guide. Create Space USA. 


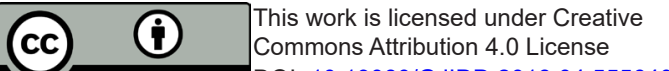

BY DOI: 10.19080/GJIDD.2018.04.555640
Your next submission with Juniper Publishers will reach you the below assets

- Quality Editorial service

- Swift Peer Review

- Reprints availability

- E-prints Service

- Manuscript Podcast for convenient understanding

- Global attainment for your research

- Manuscript accessibility in different formats ( Pdf, E-pub, Full Text, Audio)

- Unceasing customer service

Track the below URL for one-step submission https://juniperpublishers.com/online-submission.php 